\title{
La educación musical como escuela de creatividad a partir del pensamiento de Alfonso López Quintás
}

\author{
Esteban Beltrán-Ulate * \\ https://orcid.org/0000-0001-6066-443X
}

Recibido: 08 de abril de 2020 • Aceptado: 16 de junio de 2020

\section{Resumen}

El artículo asume la «teoría de los ámbitos de realidad» del filósofo Alfonso López Quintás para analizar el rol de la educación musical como escenario para la formación humana en creatividad. Desde el enfoque de la filosofía del personalismo dialógico del autor, se realiza una crítica a la concepción de sociedad del vértigo, se propone un cambio de mirada, del enfoque objetivo al dialógico, en el que el ser humano sea un ser re-creador de sentido, un ser creativo, desde la práctica educativa de las artes musicales.

Palabras clave: Educación, música, personalismo, educación artística.

* Licenciado en Docencia en Enseñanza de la Música de la Universidad Estatal a Distancia (UNED), Costa Rica. Estudiante de maestría en Docencia de la Universidad Continental de las Ciencias y las Artes (UCCART), Costa Rica. Profesor de Historia de la Música en la UCCART. Correo: esteban.beltran@uccart.ac.cr 


\title{
Musical education as a school of creativity based on the thinking of Alfonso López Quintás
}

\begin{abstract}
Summary
This article takes on the «theory of the realms of reality» from the philosopher Alfonso López Quintás, in order to analyze the role of musical education as a stage for human formation in creativity. From the author's philosophical approach on dialogical personalism, a critique is made of the conception of vertigo society and a change of focus is proposed, from an objective focus to a dialogical focus, in which the human being is considered a re-creator of meaning, a creative being, from the educational practice of the musical arts.
\end{abstract}

Key words: Education, music, personalism, art education.

\section{L'éducation musical comme école de créativité à partir de la pensée d'Alfonso López Quintás}

\section{Résumé}

Cet article part de la «théorie des domaines de la réalité» du philosophe Alfonso López Quintás afin d'analyser le rôle de l'éducation musicale en tant qu'scénario pour la formation humaine en créativité. D'après la pensée dialógico-ambital personnaliste de l'auteur, l'article fait une critique à la conception de la société du vertige et propose de changer le point de vue pour passer de l'approche objective au dialogique, dans lequel l'être humain est un être re-créateur du sens et créatif dès la pratique éducative des arts musicaux.

Mots-clés: Éducation, musique, personnaliste, éducation artistique. 


\section{Introducción}

El retorno a las fuentes filosóficas es una tarea permanente para aquellas escuelas contemporáneas que pretendan desarrollar planteamientos firmes y propuestas prácticas que aspiren a impactar de manera eficiente sobre las poblaciones con las que están trabajando. En el campo educativo, mucho se habla en la actualidad sobre innovación y calidad, términos que se han convertido en mantras de las entidades encargadas de supervisar los procesos educativos en el nivel local y regional, así como en el ámbito nacional e internacional.

El objetivo del presente artículo radica en escrutar el pensamiento del filósofo Alfonso López Quintás, para así, desde su teoría, iluminar un campo en particular, en este caso el de la educación musical. Es importante recalcar que el autor, si bien ha incursionado en reflexiones sobre la educación y la música, no ha perfilado un estudio profundo, en específico, sobre la educación musical, por lo que este texto resulta óptimo, dado que asume los principios fundantes del autor y los derrama en la esfera de la formación musical.

No ofrecer una lectura de la educación musical, fundamentada en teoría robusta, puede ser fatal, pues permitirá seguir girando en círculos epistemológicos o, peor aún, asumir como novedad nociones que son las mismas, pero bajo ropajes distintos. La educación del siglo XXI demanda, no solo una comprensión del ser humano como un ser integral, sino también una clara comprensión del llamado ético frente a los constantes desafíos que se asumen día a día como humanidad.

El plan utilizado para el presente estudio parte de una caracterización del contexto social de la actualidad, el cual se ve reflejado en el campo educativo, para luego presentar la teoría de los modos de unidad del autor, noción vigorosamente fundamentada en una concepción personalista de ser humano que irradia la esfera ética y estética; a partir de esto, se focaliza la concepción del autor español sobre la música, para así, por conducto del investigador del presente estudio, avanzar hacia la reflexión de la educación musical desde una perspectiva cimentada en la teoría de López Quintás. Finalmente, se procede con el enunciado de las conclusiones del estudio.

\section{Contra el vértigo}

El siglo XX ha dejado una huella irreparable en la sociedad, el progreso no necesariamente va de la mano con el respeto a la humanidad, mucho menos a la naturaleza. Las heridas de las guerras mundiales, los conflictos regionales al margen de fronteras, los desastres biotecnológicos, las acciones terroristas y los desastres naturales, por mencionar algunos de los sucesos, han sido la antesala de una sociedad que en el siglo XXI es cada vez más individualizada y, bajo la mezquina ilusión de la aldea global, virtualizada; las heridas en las relaciones humanas van acrecentándose cada vez más. Lo anterior se evidencia en los dramas humanos, de las migraciones y las tendencias políticas que han vaciado de bienestar social a las naciones, dejando estas a la intemperie frente a crisis sanitarias, como en el caso del COVID-19. 
Esta crisis social encuentra su raíz en el egoísmo, caracterizado por López como:

El individualismo egoísta lanza al hombre a las experiencias de vértigo, y en ellas se exacerba al máximo (...) Si soy egoísta, tiendo a considerarme altaneramente como el centro del universo y a satelizar en torno a mí los seres que me rodean (...) Al dejarme llevar de mis apetitos, me parece que voy a adquirir una plenificación personal rápida y conmovedora. Pero me equivoco ${ }^{1}$.

La sociedad del vértigo es una realidad compuesta por individuos egoístas, que son incapaces de reconocer al otro en su diversidad, este modus vivendi desplaza la relación por la transacción, por lo tanto, todo acto entre humanos pasa a ser gesto infértil, motivado por apetitos individuales y deseos de satisfacción instantánea. Así, la sociedad del vértigo se encuentra reflejada en las instituciones, lo cual facilita una reproducción del modelo de manera estructural, llevando incluso a convertirse en una ideología que se comunica en el diario vivir. Pero, el gran problema que no se avizora con claridad es que «Dominar y Poseer sólo son posibles respecto a objetos. Y los objetos se hallan inevitablemente fuera del hombre» ${ }^{2}$; por tal razón, es necesario superar esta encrucijada de vértigo, la cual no es nada más que «un proceso espiritual que comienza con la adopción de una actitud egoísta» ${ }^{3}$, la humanidad misma en un laberinto y propiciar una sociedad centrada en la persona.

En el siglo XX, en Francia surge un movimiento denominado personalismo. Emmanuel Mounier de Grenoble es una de las principales voces de esta tendencia, la cual asume a la persona como eje de toda política y economía, se concibe al ser humano abierto a la relación, en una nueva visión de sociedad que es capaz de superar los antagonismos y las visiones reductivistas de las ideologías que plasman una concepción antropológica truncada. En el marco de esta escuela de pensamiento, el filósofo López Quintás plasma una teoría que parte de la crítica a la concepción de vértigo, y enciende una teoría del encuentro, mediante la cual se propone, siguiendo las tesis de Ferdinand Ebner, ejercer una revolución cultural, ya que «debemos recordar que la cultura es esencial a la vida del hombre» ${ }^{4}$.

Estos desafíos merecen una atención especial, por parte de la educación, ya que esta se ha reconocido con un mecanismo de movilización social, y de transformación de los pueblos. López reconoce que la sociedad actual presenta grandes desafíos para la educación, como él mismo indica: «Los centros educativos no disponen de métodos eficaces para detener la caída de la vida cultural en el vacío y ayudar a niños y jóvenes a configurar formas auténticas de pensamiento riguroso y vida creativa» ${ }^{5}$, es pertinente, frente a este escenario, replantear la dinámica educativa para propiciar un giro trascendental del vértigo a la creatividad. Ese es el objetivo de este estudio, delinear una ruta desde el ámbito de la educación musical.

\footnotetext{
${ }^{1}$ Alfonso López, La cultura y el sentido de la vida (Madrid: Rialp, 2003), 30.

${ }^{2}$ Alfonso López, El poder transfigurador del arte (San José: Editorial Promesa, 2013), 54.

3 López-Quintás, Alfonso, «La defensa de la libertad interior y la configuración de un nuevo humanismo», Thémata. Revista de Filosofia, n. ${ }^{\circ} 10$ (1992): 533-535, acceso: 25 de enero de 2021, http://institucional.us.es/revistas/themata/10/09\%20lopez.pdf

${ }^{4}$ López-Quintás, Alfonso, «El carácter relacional de la creatividad humana», Revista Espiga, n. ${ }^{\circ}$, (2003b):1-18, acceso: 25 de enero de 202, https://revistas.uned.ac.cr/index.php/espiga/article/view/777/665

${ }^{5}$ López, Alfonso, Liderazgo Creativo (Argentina: Editorial Brujas, 2007), 28.
} 


\section{Teoría de los ámbitos de realidad}

López es heredero de la fuente filosófica del personalismo dialógico ${ }^{6}$ y de las tesis éticas de Zubiri ${ }^{7}$, lo cual le permite fundamentar su teoría antropológica, que confronta la concepción moderna de ser humano como ser finito. Para el autor, en el ser humano hay una fuente inagotable de sentido que imposibilita su totalización. Si bien, en él hay una condición innata de trascendencia, el egoísmo que crece en los individuos es capaz de trastornar el mundo de las relaciones y limitar a la mera transacción de información con fines prácticos e infértiles. En otras palabras, el individuo colmado de egoísmo en estado de vértigo es capaz de llevar a nivel de cosas a las personas. Sin embargo, es frente a esta escena de sociedad desorientada que López plantea reorientar, saliendo del fango objetivista, al mundo de los ámbitos de realidad ${ }^{8}$.

Para el autor que ilumina el presente estudio, la realidad no es una simple lectura objetiva unidireccional en procura de satisfacer placeres individuales. Existe un mundo de realidades abiertas, por medio de las cuales el ser humano es capaz de crecer en su proyecto de vida personal y comunitario, incluso, también planetario. Para una comprensión de la teoría de los ámbitos de relación, según López ${ }^{9}$, se deben identificar dos niveles: las actitudes humanas dirigidas a los objetos, constituyen el nivel 1 de realidad y conducta; por otro lado, las realidades no objetivas que pueden ser pensadas, como el amor, la amistad, la solidaridad, entre otras, pertenecen al nivel 2. Una vez descubiertos los niveles precitados, para López ${ }^{10}$, los ámbitos de realidad se identifican de tres modos: (a) las personas, (b) realidades que no son personas ni objetos, como un instrumento musical, una poesía, una escultura, entre otros, (c) los campos de relación entre el ámbito 1 y 2, ahí es donde se identifica el encuentro, esto evidencia la condición verdadera y esencial de la humanidad, «El auténtico entorno del hombre no está formado por objetos yuxtapuestos sino por ámbitos entretejidos» ${ }^{11}$.

La teoría de los ámbitos expuesta por López Quintás supera la visión objetiva del ser humano frente a la realidad como un conglomerado de objetos, en el que puede disponer de cada elemento como una pertenencia; el giro del autor permite reconocer al ser humano dentro de un entramado de sentidos, donde las emociones son una extensión de la realidad personal que le permite dialogar con otras realidades, recreando nuevos escenarios, e incluso despegando nuevos lenguajes para interpretar-se en el mundo. Lo que parecen simples objetos, desde la mirada renovada, es una infinidad de posibilidades a partir de las cuales el ser humano es capaz de co-crear. Desde esta óptica, el arte juega un rol fundamental, y en el caso particular de la música, se abren una serie de posibilidades para la re-creación de sentidos: "La música es radicalmente un tejido de relaciones. Empieza a existir cuando dos sonidos se interrelacionan expresivamente (...) Al admirar una obra

\footnotetext{
${ }^{6}$ Muñoz-García, Juan José, «Superación del objetivismo mediante experiencias creativas en la filosofía de López Quintás», Revista Quién, n. ${ }^{\circ} 1$ (2015): 133-154, acceso: 25 de enero de 2021, http://www.personalismo.org/wp-content/uploads/2016/06/Estudio-7.pdf

${ }^{7}$ López, La cultura ..., 30.

${ }^{8}$ Muñoz-García, «Superación del objetivismo..., 133-154.

${ }^{9}$ López, El poder..., 54.

${ }^{10}$ Ibíd.

${ }^{11}$ Ibíd., 32.
}

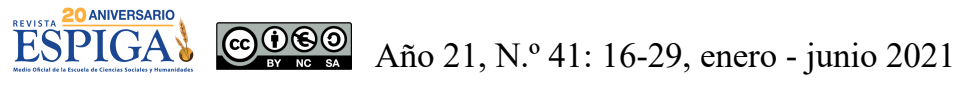


musical, celebramos la fecundidad de las relaciones, que dan lugar a modos diversos de encuentro» ${ }^{12}$.

La música es un terreno fértil para la estimulación de ambientes que permitan retornar al mundo de las relaciones y desplazar cada vez más la concepción de vida estéril, objetivadora. Es importante indicar que el presente estudio no abandona la posibilidad de lograr este cometido por conducto de otras artes o por medio de otras disciplinas; sin embargo, en razón del objetivo que orienta el presente escrito, se acomete una reflexión puntual sobre el alcance de la música en esta tarea, pues en general, el arte en su esencia «no sólo quiere producir obras, suscitar experiencias conmovedoras, expresar contenidos de uno u otro orden; intenta ponernos en presencia de formas excelentes de realidad y de existencia personal ${ }^{13}$; empero, la música es esfera que asume el presente estudio como fuente de creatividad, desde el reconocimiento de formación musical como desafío, ya que es en el acto poético de la educación donde las fibras del diálogo permiten accionar el alcance de una transformación profunda de la sociedad hacia una civilización de la persona.

\section{La música como fuente creativa}

La música, desde sus orígenes, ha estado vinculada al ser y quehacer cotidiano, al formar parte de las actividades más necesarias como innecesarias, de modo que presenta un dual carácter de necesidad y libertad; además de esto, conforme se dioel avance de los instrumentos de agricultura, caza y guerra, de manera proporcional, también se dio la especialización en el desarrollo de artefactos sonoros, que más adelante adquirirían la categoría de instrumentos musicales, cuyo objetivo es expresar, de manera sonora, sentidos concretos y abstractos. La especialización de la música en manos de una lectura teórico-matemática, con especial atención desde los abordajes de la cultura griega antigua, desencadenó un tratamiento racionalista predominantemente hasta llegar a la época moderna, donde con contundencia, de la mano del desarrollo de una tipografía musical, se logró plasmar la música como lenguaje escrito y matemáticamente digerible. Es importante recordar que las leyes racionales rigen las estructuras musicales occidentales en la modernidad; además, la libertad y la fuerza de sentido son contundentes en el corpus musical moderno, donde lejos de ejercer una transacción matemática, el oído humano logra una lectura simbólica y semántica de los discursos musicales, desmembrando hilos de sentidos y emociones en cada pasaje musical, tal como ejemplifica el siguiente texto:

Yo me siento obligado a toda realidad que encuentro, sea una sonata de Haydn, sea una persona o una comunidad, pero tal obligación no es una coacción, sino al revés, es un tipo de compromiso que me eleva a una forma superior de libertad, de autonomía en vinculación. Si alguien toca bien una obra musical, obedece a la partitura, al autor, al estilo del autor, pero se siente más libre que nunca, con libertad creativa $^{14}$.

\footnotetext{
12 Ibíd., 64.

${ }^{13}$ Ibíd., 71.

${ }^{14}$ López-Quintás, Alfonso, «Cómo educar en ética por vía del descubrimiento», Revista EDETANIA, n. ${ }^{\circ} 51$ (2017): 37.
} 
Para el autor, enfrentarse a una obra de Haydn no se limita a un tratamiento llano de la obra, aunque esto no implica que no sea posible una lectura objetiva, unidireccional que permita extraer unas definiciones para objetivos individuales; sin embargo, la vida no termina ahí, es más bien a partir de un cambio de mirada que se logra salir de la concepción objetivante y se procede a una salida que permita cruzar las fronteras del contenido para abrazar el sentido, siempre rebosante, ahí en medio de la dinámica con las tres dimensiones de los ámbitos de realidad que se desnuda un universo de múltiples sentidos y en el acto de la escucha se re-intepreta y se cocrea la vida.

Oigo una obra musical; asumo activamente las posibilidades creativas que me ofrece y vuelvo a recrearla personalmente, como si fuera el autor de la misma. Esta es una experiencia reversible. Yo configuro la obra, pero lo hago en cuanto me dejo configurar por ella. No la domino; la configuro. No me dejo dominar por ella, sino configurar ${ }^{15}$.

La vivencia musical articula los tres ámbitos de relación, la persona como eje de la experiencia se ve inmersa en un escenario de multiplicidad de sentidos y emociones, sin que la racionalidad exacerbada asuma un rol de tirano frente al instante. El evento comprendido como encuentro ${ }^{16}$ permite una renovación del ser humano en su dimensión personal, la cual le permite, a la postre, una modificación en su mundo de relaciones local, lo que facilita una transformación de su inmediatez como preámbulo para la transformación cultural necesaria en tiempos de vértigo.

\section{Educación musical como escuela de creatividad}

Frente al desafío de la sociedad del vértigo y la posibilidad de la música como tierra fértil para el surgimiento de una nueva sociedad por medio de la experiencia estética que deriva de la teoría de ámbitos de realidades, emerge la impostergable tarea de a educación musical, como escenario que estimule la nueva ciudadanía que afronte la vida desde una lectura multidimensional, de manera creativa, como una escuela de sentido.

La vida no puede seguir sino asumida como un cúmulo de objetos al servicio de las vanidades y egoísmos humanos; la humanidad no puede ser la plaga que azote las tierras, no puede ser el veneno en los ríos, no puede ser la oclusión de la vida sobre el planeta Tierra. Las realidades son diversas y multidimensionales, el ser humano debe reconocer que lo que le rodea no son cosas, son posibilidades para continuar con su proyecto de vida, vida en comunidad.

La Educación Musical es una escuela de creatividad, donde la invitación a vivir desde una perspectiva dialógica sea una tarea permanente, donde la realidad abierta sea un jardín de posibilidades para reparar el mundo:

Las realidades no son ni personas ni objetos, por ejemplo, un instrumento musical. Éste ofrece al interprete ciertas posibilidades de sonar y puede establecer con él una relación reversible de mutuo influjo y enriquecimiento. Esta relación mutua, bidireccional implica

\footnotetext{
${ }^{15}$ López, El poder..., 51

${ }^{16}$ Ibíd.
} 
un modo de unidad superior a la unidad tangencial que tiene con el piano el que se limita a acariciar sus materiales ${ }^{17}$.

Tal como lo expone el autor que inspira el presente estudio, el ser humano puede determinar un instrumento musical en dos vías, como un mero objeto, cuantificable, medible; o desde un segundo nivel como una dimensión de posibilidades, en las que puede entrar en contacto, por conducto de la actitud que asuma frente a él, actitud entretejida por emociones, razón cálida, donde el tocar (lo objetivo) es superado por la caricia (trascender con lo que se anhela) y se alcanza una dimensión donde un nuevo lenguaje (poético) es posible, esto permite el encuentro, dicha relación es una constante re-creación de sentido incesante en doble sentido, lo que López ${ }^{18}$ denomina reversible. Una vez finalizado el encuentro, el juego diacrónico pasa al flujo de lo sincrónico y las huellas del diálogo permanecen en la memoria del ser humano como experiencias estéticas que animan predisposiciones éticas.

La educación musical, vista desde el enfoque de Alfonso López Quintás, debe ser un escenario donde prime ante todo la posibilidad del encuentro cara a cara con la ejecución musical, vivenciar la música, sobre todo, por medio de su interpretación. Esto no implica que, frente a la imposibilidad de la ejecución instrumental, la simple audición musical sea depreciada, sino que es en la vivencia por medio de la ejecución que se posibilita un escenario colmado de posibilidades de sentido, que supera en dimensiones la simple escucha de música. Para un acercamiento reflexivo de la teoría del ámbito de las realidades desde Lopéz aplicado a la Educación Musical, se plantea asumir desde tres aristas: (a) la audición musical como fidelidad a la tradición (b) la ejecución de la obra musical como libertad y norma y (c) la composición musical como co-creación.

\section{Audición musical como fidelidad a la tradición}

La audición musical debe ser una acción permanente dentro de la educación musical, pero bajo una serie de lineamientos que permitan un adecuado ejercicio para la formación de la persona. Si bien la música se manifiesta de múltiples maneras, a partir de las diferentes estructuras culturales que dan paso a la manifestación sonora, es importante reconocer que existe una estetización de las manifestaciones artísticas al punto de convertirlas en objetos de consumo ${ }^{19}$, de tal manera que una pieza musical, sin dejar de ser una manifestación sonora intencional dentro de una estructura cultural, ha sido producida, mas no creada, con un objetivo individualista que aspira a la satisfacción de una necesidad ególatra, con tintes económicos, en algunos casos. A partir de lo anterior, queda claramente expuesto que no todo lo que se llame a sí mismo música, es una posibilidad para el encuentro creativo de las personas.

La audición musical, como terreno fértil para la educación musical, debe recurrir a formas musicales que afirmen al ser humano; desde la perspectiva del autor del presente artículo, se destaca que esto no excluye el atonalismo, se debe ser cauto y no pretender que únicamente la música académica (formal) y tonal es la llamada a

\footnotetext{
${ }^{17}$ López, Alfonso, La cultura y el sentido de la vida (Madrid: Rialp, 2003), 28.

18 Ibíd.

${ }^{19}$ Beltrán-Ulate, Esteban, «El desafio de la educación artística en Tiempos Hipermodernos», Revista Espiga, Vol. 15, n. ${ }^{\circ} 32$ (2016): 145-52.
} 
acometer esta tarea, también es posible acudir a las formas regionales y populares, teniendo presente, en todo caso, que estas no reduzcan a la persona como objeto de consumo sonoro únicamente.

La obra musical debe asumir al Otro como un quien que escucha, no solamente como un receptor de información. Por eso, en situaciones donde la música cumple un rol utilitario y mecánico, es improbable un juego de posibilidades, tal como lo expone López $^{20}$ : «La repetición a que son sometidos los temas musicales en los anuncios comerciales no responde a un impulso creador de una estructura musical: es puramente mecánica y ejerce un efecto trivializador»».

La música, como fuente de tradición, debe ser asumida con rigor y no a la ligera, no es suficiente con exponer música de Mozart a los estudiantes como si fuera una receta mágica que les convertirá en genios creativos, no se puede asumir la música como manipulación, como lo define López ${ }^{21}$ «reducir de rango, envilecer, destruir moralmente»; no se debe asumir la música como un medio para un fin, ya que la música es en sí misma un ámbito de realidad que, al entrar en diálogo con la persona, posibilita una infinidad de posibilidades creativas.

La audición de obras musicales debe ser un acto responsable, reconociendo el valioso contenido histórico en ellas y la tradición que envuelve, no es conveniente, en primer lugar, exponer a golpe de costilla a los estudiantes a obras de extensa duración, ya que lejos de cautivarlos, se puede llegar a adormecerlos y propiciar juicios injustos sobre las obras que, en la mayoría de los casos, tienen que suspenderse antes de verlas finalizadas, lo cual es aún más doloroso, ya que la obra es cercenada, como claramente lo expone López: «La utilización reduccionista de los bienes culturales puede llegar a constituir un atentado al patrimonio de la Humanidad $»^{22}$.

Por tal razón, desde la educación musical debe proveerse de un plan de audición musical que permita un avance progresivo de obras, de la mano de una guía de escucha que no se limite a los elementos teóricos o históricos, sino que avance al nivel de las emociones y de la reflexión en torno a los sentimientos. Aunado a esto debe posibilitarse un reconocimiento del contexto cultural de los estudiantes para que así el profesor sea capaz de establecer una agenda de obras que permita la identificación de elementos también accesibles a sus contextos sonoros, sin que esto implique la imposibilidad de acceder a repertorio universal.

La audición musical permite acceder, a quien escucha, a una tradición que articula diversos sentidos y, que a la vez es heredera y progenitora de historia y cultura, ante la escucha de una obra musical, se descorcha la historia, «Cada estilo musical es fruto de la confluencia de diversos elementos en un determinado tiempo y lugar, y, una vez lograda la perfección, colabora al formar otros estilos» ${ }^{23}$.

Antes de acudir al repertorio musical universal, siguiendo las tesis de Paulo Freire, cabe reflexionar respecto al contexto próximo, por lo que el educador musical debe preguntarse ¿Cómo hablar de ópera y Beethoven si nunca han cantado un Aria y no conocen a alguien que se llame Ludvig? Así pues, el camino para la educación musical, basada en la audición musical, demanda una planificación progresiva y con

${ }^{20}$ López, La cultura y..., 64.

${ }^{21}$ López-Quintás, «La defensa de..., 533-535.

${ }^{22}$ López-Quintás, «La defensa de..., 165.

${ }^{23}$ López, El poder.., 112. 
base en el contexto cultural. Atender esta tarea permitirá ser fiel a la tradición de una humanidad que se ha construido a sí misma como un proyecto artístico, donde cada generación está llamada a continuar haciendo resonar la tradición, manifestando su fidelidad.

\section{Ejecución de la obra musical como libertad y norma}

López $^{24}$ considera que no hay dilema entre las nociones de libertad y norma, tal como lo asume parte de la opinión popular, y que ese espejismo queda disipado en la vivencia musical, especialmente en la ejecución instrumental. Ya que se puede ser libre, respetando la ley como mandato, enseñanza y guía que permite el buen conducir.

Para vivir de forma creativa, necesitamos asumir las posibilidades que nos ofrece el entorno. Entre tales posibilidades figuran las normas que son fecundas y vienen propuestas por alguien que está dotado de autoridad, de poder promotor. Si asumimos activamente las normas que nos vienen sugeridas desde fuera, éstas no sólo no anulan nuestra capacidad de ser libres sino la incrementan y llevan a plenitud. Tales normas entran a formar parte de nuestra actividad creativa ${ }^{25}$.

La descripción anterior deja sobre relieve cómo, en la ejecución instrumental, se hace patente esta dinámica relación entre norma y libertad. Pues el intérprete parte de una norma que está dispuesta en una partitura que viene a ser la ley escrita, para posteriormente ser encarnada por medio de un instrumento o incluso mediante la voz, es ahí donde entra en juego, de múltiples formas, la creatividad humana, la cual, sin dejar de responder a la tradición escrita, se reaviva y se torna como recreación sonora de una obra artística. Es así como el ejecutante logra integrar modos de realidad y asume como interprete una dimensión creativa. No es solamente un ejecutante (reproductor de la norma), sino que se configura en un intérprete (plano creativo) al posicionar sus impresiones íntimas en la obra. Como describe López ${ }^{26}$ :

El buen intérprete obedece a la partitura, que es su cauce expresivo, el principio de su actuación artística, su impulso creador. El buen intérprete obedece a la partitura, que es su cauce expresivo, el principio de su actuación artística, su impulso creador. Sabe que sin la obra no sería nada, estaría condenado a la inexpresividad. Cuando se entrega a la tarea de recrear la obra, advierte que gana una libertad interior gozosísima, se ve dotado de la capacidad de crear toda una trama sonora, llena de belleza y expresividad.

Siempre se debe ser cauto ante las debilidades humanas y el egoísmo que crece como mala hierba, debe ser vigilado, así que también en la vida del intérprete se debe reflexionar que no emerja el vicio de ambición, el vicio del deseo de sobresalir y, por ende, la objetivación de la vivencia musical, al punto de reducirla en un escenario de vértigo; si se es egoísta en la ejecución instrumental, se reduce la experiencia

\footnotetext{
${ }^{24}$ López-Quintás, «La defensa de..., 533-535.

${ }^{25}$ López, El poder..., 112-113.

${ }^{26}$ López-Quintás, Alfonso, «Necesidad de un método de formación integral», Revista Persona y Derecho, n. ${ }^{\circ} 50$ (2004): 177-118, acceso: 25 de enero de 2021,

https://revistas.unav.edu/index.php/persona-y-derecho/article/download/31870/26882/
} 
musical a la mera competición, que es una forma más de vértigo y ambición. No hay éxtasis, simplemente un gesto ruin de violencia encubierta de ropajes artísticos.

La educación musical es el espacio idóneo para templar el espíritu de las personas quienes, por medio de la ejecución instrumental, logren asumir la integración entre norma y libertad, es en los espacios de formación instrumental donde los profesores que de antemano deben estar libres de las cadenas del vértigo, los que propiciarán ambientes de cuidado donde por medio de la modelación estimularán y potenciarán en el estudiantado una motivación para recurrir a la norma musical (partitura) y, a través del diálogo con la tradición (audición musical) y la ejercitación de técnicas, alcancen recrear las obras y participar del patrimonio universal del lenguaje musical, reviviendo la música en su origen como un constante nacimiento, «rehacerla creativamente, tanto el que la interpreta como el que la oye. Uno descubre la obra cuando se sumerge en ella y la vive como si la estuviera gestando» ${ }^{27}$.

\section{Composición musical como co-creación}

Una educación musical que, en primera instancia, potencie la audición musical y la ejecución instrumental será la plataforma idónea para avanzar al nivel de la composición musical, esto sin implicar un abandono a las fases precedentes. Toda educación musical debe aspirar a llevar a las personas a la fase creadora, donde se unen en espíritu a los miles de compositores que han dejado huella musical en la historia de la humanidad.

Todo es un proceso, por lo cual se debe ser prudente y, un buen educador musical, tendrá caracterizado el momento adecuado según las características de sus estudiantes para avanzar a la etapa composicional, etapa que seguramente ya habrá iniciado de manera celada por parte de los estudiantes, quienes animados por una fuerza creadora se lancen al desafío. En todo caso, el educador musical debe marcar, con astucia, las pautas para que el impulso creativo, como fuerza ciega, sea encaminado por medio de la voz serena de la tradición hasta alcanzar un camino seguro.

Es inadecuado asumir, mediante un proceso de formación masificado, que todos los estudiantes están preparados, a la vez, para avanzar a la fase de composición; por eso, en medio de escenarios educativos multitudinarios, el educador debe ser astuto, prudente y creativo para encaminar y potenciar a los que se están preparando para dicha faena artística, mientras a los que no, continuar abordándolos en las fases anteriores.

La composición, como fase culminante de la educación musical, permite al estudiante abrazar las vivencias previamente asumidas para que, desde un contexto definido, emerja la voz personal que se agrupa con la tradición, vista como comunidad que aguarda al hermano para abrazarlo en medio de una nueva obra musical.

Educar en la composición musical implica asumir el diálogo con la tradición y el horizonte del porvenir; en el lenguaje es el horizonte que divide el ayer del mañana.

${ }^{27}$ López, 2017, 31.

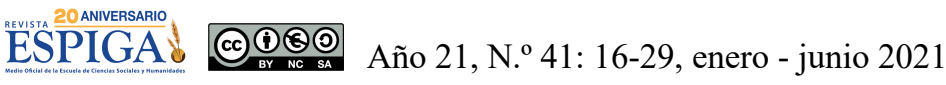


Acompañar a los estudiantes a este nivel es un acto generoso y esperanzador, que todo educador musical debe anhelar, es el fruto de la pedagogía como donación.

\section{Educación musical, fuente creativa}

La educación es un acto generoso de esperanza en la humanidad, esa debe ser su motivación, por lo tanto, en donación. Por su parte, la educación musical es una fuente de creatividad, porque su contenido es la música, una forma artística, por lo tanto su ejercicio debe estar orientado a cumplir las capacidades creativas personales y comunitarias. La Educación Musical debe librarse de las condiciones manipuladoras que ofrezca la sociedad del vértigo para convertirse en un medio para su labor; la educación musical debe reconocer que la experiencia musical es el motor de su actividad y que la creatividad es la disposición que se anhela alumbrar en cada una de las personas que asuman dicho desafío.

Ser creativo consiste en recibir activamente posibilidades de actuar con sentido, es decir, valores. Tal asunción activa implica participación. El hombre gana poder creador cuando participa en grandes valores. Esta participación se expresa en una forma de lenguaje que será compartido fácilmente por quien se halle inmerso participativamente en la misma corriente de valor ${ }^{28}$.

En muchos países la educación musical forma parte de una malla curricular que aspira, según sus postulados, a una formación integral de la ciudadanía que responda a los desafíos nacionales como internacionales, planetarios incluso. Por tal razón, la educación musical, hoy más que nunca, no debe perder su norte y afianzar sus raíces por conducto de una definición clara de sus propósitos y métodos. La educación musical debe librarse de ser el comodín de la estructura curricular; así mismo, debe superar los antagonismos evaluativos que polarizan al estudiante entre lo cuantitativo y cualitativo. No será posible una educación musical que potencie creatividad mientras los planes de estudio respondan, «sea medios para un fin», y mientras los educadores musicales vivan la depresión del «artista que nunca se fue».

La educación musical creativa no tiene un punto de partida específico, puede iniciar en cualquier lugar, es una explosión de éxtasis que ilumina cualquier noche de vértigo; así pues, donde la educación musical brille con generosidad, sin ambición, ahí mismo se encuentra una sede de esperanza para una educación integral, que aspire integrar al ser humano con el mundo, por medio de un diálogo con las realidades circundantes de manera reversible, sin que medie un deseo individualista y egoísta de consumo. Ahí donde la educación musical asuma la vivencia musical en escuchar, interpretar y componer se iluminará la sociedad con una nueva civilización, donde «Ser creativo significa asumir activamente las posibilidades que nos ofrece el entorno para dar lugar a algo nuevo dotado de valor» ${ }^{29}$.

${ }^{28}$ López 2003, 29.

${ }^{29}$ López 2002, 77.

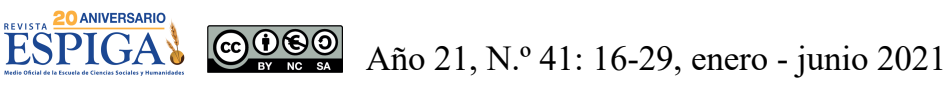




\section{Conclusión}

Alfonso López Quintás ilumina, desde su perspectiva del personalismo dialógico, el mundo de las relaciones y lanza una propuesta para acometer un giro que posibilite una nueva civilización, donde la persona humana se logre desataviar de las conductas que afirman el vértigo en la sociedad, para asumir una actitud creativa ante la vida hacia el éxtasis como condición de felicidad y solidaridad humana.

A partir de las ideas del autor español, se realiza una transición de las reflexiones en materia de música para asumir, desde el escenario de la educación musical, un itinerario que permita alcanzar la creatividad y disposición ante la vida, a partir de su vivencia en la práctica musical. El artículo asume una posición radicalmente responsable por parte de la educación musical dentro de la formación integral del ser humano, liberándola de cualquier concepción decorativa y fundándola sobre la necesidad de promover una civilización de personas creativas, capaces de lidiar con la norma y la libertad, animadas por las voces de la tradición y con una llama que arde por aportar con un mensaje que se sume a las voces de la comunidad.

Educar en música es llevar a hombres y mujeres al horizonte de sus posibilidades en el marco de su vida como proyecto y que a partir de la realidad contextual de la que son parte puedan ejercer un acto generoso, donativo y creativo, que sea cedido de manera solidaria a la humanidad; para que, de tal manera, se lleve a cabo la cocreación de una nueva civilización, donde el vértigo es una posibilidad debido a la falibilidad humana, donde la creatividad será el instrumento de la esperanza aún en tiempos de oscuridad.

\section{Formato de citación según APA}

Beltrán-Ulate, E. (2021). La educación musical como escuela de creatividad, a partir del pensamiento de Alfonso López Quintás. Revista Espiga, 21 (41), páginas 16-29.

\section{Formato de citación según Chicago-Deusto}

Beltrán-Ulate, Esteban. «La educación musical como escuela de creatividad, a partir del pensamiento de Alfonso López Quintás». Revista Espiga 21, n. ${ }^{\circ} 41$ (enero-junio, 2021): páginas 16-29. 


\section{Fuentes consultadas}

Beltrán-Ulate, Esteban. «El desafío de la educación artística en Tiempos Hipermodernos». Revista Espiga 15, n. 32 (2016): 145-52.

López-Quintás, Alfonso. «Cómo educar en ética por vía del descubrimiento». Revista EDETANIA, n. ${ }^{\circ} 51$ (2017): 27-43.

López, Alfonso. El poder transfigurador del arte. San José: Editorial Promesa, 2013.

López, Alfonso. Liderazgo Creativo. Argentina: Editorial Brujas, 2007.

López-Quintás, Alfonso. «Necesidad de un método de formación integral». Revista Persona y Derecho, n. ${ }^{\circ} 50$ (2004): 101-120. Acceso: 25 de enero de 2021. https://revistas.unav.edu/index.php/persona-yderecho/article/download/31870/26882/

López, Alfonso. La cultura y el sentido de la vida. Madrid: Rialp, 2003.

López-Quintás, Alfonso. «El carácter relacional de la creatividad humana». Revista Espiga, n. ${ }^{\circ} 7$ (2003b): 1-18. Acceso: 25 de enero de 2021.

https://revistas.uned.ac.cr/index.php/espiga/article/view/777/665

López-Quintás, Alfonso. «El desarrollo de la vida personal». Pensamiento y Cultura 5, n. ${ }^{\circ} 1$ (2002): 69-81. Acceso: 25 de enero de 2021.

https://pensamientoycultura.unisabana.edu.co/index.php/pyc/article/view/1083

López-Quintás, Alfonso. «La defensa de la libertad interior y la configuración de un nuevo humanismo». Thémata. Revista de Filosofía, n. ${ }^{\circ} 10$ (1992): 533-535. Acceso: 25 de enero de 2021.

http://institucional.us.es/revistas/themata/10/09\%20lopez.pdf

Muñoz-García, Juan José. «Superación del objetivismo mediante experiencias creativas en la filosofía de López Quintás». Revista Quién, n. ${ }^{\circ} 1$ (2015): 133154. Acceso: 25 de enero de 2021. http://www.personalismo.org/wpcontent/uploads/2016/06/Estudio-7.pdf 